\title{
GINÁSTICA GERAL NA ESCOLA: UMA PROPOSTA METODOLÓGICA
}

\author{
Nara Rejane Cruz de Oliveira* \\ Luiz Fernando Costa de Lourdes **
}

\section{RESUMO}

Este trabalho tem por objetivo discutir a Ginástica como conteúdo da Educação Física escolar, por meio da Ginástica geral como proposta metodológica. Tal proposta tem como perspectiva a integração das diversas manifestações gímnicas e os outros componentes da cultura corporal, sendo sua principal característica a ausência da competição. PALAVRAS-CHAVE: ginástica-ginástica geral - educação física escolar.

\section{INTRODUÇÃO}

Ginástica no contexto da Educação Física escolar foi historicamente construída a partir de determinados modelos, especialmente as escolas ginásticas da Europa. O caráter esportivizado também foi uma característica marcante. No decorrer dos anos, a formação profissional em Educação Física enfatizou tais modelos, e conseqüentemente, grande parte dos professores, no contexto da prática pedagógica escolar, ora apresentam a ginástica baseada nestes modelos ou optam pela sua ausência, perante a alegação de falta de equipamentos e/ou instalações adequadas, confundindo assim, as modalidades gímnicas competitivas (artística/olímpica,

* Mestre em Educação Física pela Universidade Estadual de Campinas, Professora do Curso de Educação Física da Universidade Cruzeiro do Sul - São Paulo/SP e Membro do Comitê Científico do GTT Escola do Colégio Brasileiro de Ciências do Esporte - Gestão 2003/2005.

** Especialista em Ginástica pela academia de Educação Física da Dinamarca (Gymnastikhøjskolen i Ollerup). Professor do Curso de Educação Física da Universidade Cruzeiro do Sul e Faculdade Brasília de São Paulo/SP e Ex-integrante do Grupo Ginástico Unicamp, da Faculdade de Educação Física da Universidade Estadual de Campinas. 
rítmica, dentre outras) com a ginástica em si, gerando desta forma, a elitização de tal prática (COLETIVO DE AUTORES, 1992).

Perante estas constatações, o objetivo deste trabalho é discutir uma possível forma de intervenção pedagógica através da Ginástica como conteúdo da Educação Física escolar. Acreditamos que esta possibilidade se concretize por meio da Ginástica Geral (GG), na medida em que esta tem como perspectiva a integração das diversas manifestações gímnicas e os outros componentes da cultura corporal, sendo sua principal característica a ausência da competição.

A GG pode proporcionar, além do divertimento e satisfação provocada pela própria atividade (na medida em que busca o resgate do núcleo primordial da ginástica - o divertimento), o desenvolvimento da criatividade, da ludicidade e da participação, a apreensão pelos alunos das inúmeras interpretações da ginástica, e a busca de novos significados e possibilidades de expressão gímnica (AYOUB, 2003). As atividades são oportunidades privilegiadas, porque são geradas criativa e espontaneamente, a partir da tomada de contato com o outro, da percepção e reflexão sobre as pessoas e a realidade na qual estão inseridas. Apresenta-se então dotada de um caráter de autonomia, liberdade, o que favorece também o convívio em novos grupos, fazendo com que o indivíduo alargue as fronteiras do seu mundo e intensifique assim suas comunicações. As vivências no campo da GG têm a função de sociabilização, além de solidariedade e identificação social. Assim, podemos considerá-la como elemento privilegiado no contexto educativo.

Portanto, se for entendida e assumida como fenômeno social e historicamente produzido pelo homem, constitui-se como bem cultural, que deve ser apropriado pela população. Desse prisma, buscamos o desenvolvimento de uma reflexão sobre o seu desenvolvimento no contexto da Educação Física escolar.

No que diz respeito à Educação Física escolar, nosso entendimento é de que a mesma constitui-se como prática pedagógica, que trata política e pedagogicamente dos temas da cultura corporal (jogo, dança, esporte, lutas, ginástica), visando apreender a expressão corporal como linguagem (COLETIVO DE AUTORES, 1992). Desta forma, pode contribuir para a formação de indivíduos críticos e criativos e intervir de forma significativa em sua realidade social. 


\section{A GINÁSTICA COMO PRÁTICA PRIVILEGIADA DE EDUCAÇÃO FÍSICA}

O século XIX constitui-se um importante período para a compreensão das raízes da Ginástica moderna e da Educação Física. Entretanto, a Ginástica não é algo recente na sociedade. Segundo Rouyer (1977), sua denominação remonta aos agrupamentos desportivos gregos, como a arte de exercitar o corpo nu (em grego gymnos). Essa associação entre o exercício físico e a nudez, traz o sentido do despido, do simples, do livre, do limpo, do desprovido ou destituído de maldade, do imparcial, do neutro, do puro (AYOUB, 2003).

A partir do início do século XIX, a Ginástica passou a ser considerada científica, fruto das distintas formas de se pensar os exercícios físicos em países da Europa - Alemanha, Suécia, França e Inglaterra surgindo assim os métodos/escolas de ginástica ou Movimento Ginástico Europeu. Nesta perspectiva, buscou-se imprimir um caráter de utilidade aos exercícios físicos, em que foram negadas as práticas populares de artistas de rua, de circo, acrobatas, funâmbulos, que a apresentavam como espetáculo, trazendo o corpo como centro de entretenimento (SOARES, 1994, 1998, 2001).

Como expressão da cultura, este movimento se constrói a partir das relações cotidianas, dos divertimentos e festas populares, dos espetáculos de rua, do circo, dos exercícios militares, bem como dos passatempos da aristocracia. Possui em seu interior princípios de ordem e de disciplina que podem ser potencializados.

Para sua aceitação, porém, estes princípios de disciplina e ordem não são suficientes. Ao movimento ginástico é exigido o rompimento com seu núcleo primordial, cuja característica dominante se localiza no campo dos divertimentos (SOARES, 1998, p. 18).

Segundo Soares (1998), a Ginástica como prática científica é constitutiva da mentalidade burguesa, destacando-se pelo seu caráter ordenativo, disciplinador e metódico, além do discurso de aquisição e preservação da saúde. Ao longo do século XIX, foram inúmeras as tentativas de estender sua prática à grande massa trabalhadora urbana, que para os interesses do capital, tornava-se cada vez mais numerosa e potencialmente perigosa. 
De acordo com esse autor, é na gradativa aceitação dos princípios de ordem e disciplina formulados pelo Movimento Ginástico Europeu, bem como do afastamento de seu núcleo primordial (o divertimento), que paulatinamente a Ginástica se afirma como parte da educação dos indivíduos, como prática capaz de potencializar a utilidade dos gestos e oferecer um espetáculo "controlado" e institucionalizado dos usos do corpo, em negação aos elementos cênicos, funambulescos, acrobáticos.

No Brasil, os métodos ginásticos influenciaram sobremaneira a constituição da Educação Física e estiveram presentes nos discursos político, médico e pedagógico. Soares (1994) afirma que apesar das particularidades dos países de origem, as escolas de ginástica, de um modo geral, possuíam características semelhantes, como regeneração da raça, promoção da saúde (independente das condições de vida), desenvolvimento de vontade, força, coragem, energia de viver (para servir à pátria) e desenvolvimento da moral (intervenção nas tradições e costumes dos povos).

Precursora da Educação Física, a Ginástica científica se afirmou ao longo do século XIX como síntese do pensamento científico no Ocidente europeu e integrante dos novos códigos de civilidade, o que vai justificar sua presença no currículo escolar. Como conclui Soares:

Herdeira de uma tradição científica e política que privilegia a ordem e a hierarquia desde sua denominação inicial de Ginástica, a hoje chamada Educação Física foi e é compreendida como um importante modelo de educação corporal que integra o discurso do poder (2001, p. 113).

É neste contexto, no século XIX, que tem início o projeto de institucionalização da Educação Física no Brasil (ainda chamada Ginástica), como disciplina obrigatória nas escolas, em que os ideais eugênicos e higiênicos se faziam presentes na Educação.

Cabia à Educação Física vinculada à Educação Escolar, o papel de contribuir para a formação dos corpos eugênicos e higiênicos. Na prática, a Educação Física ressaltava por meio de seus conteúdos e metodologias os assuntos relacionados à formação da ordem, disciplina e moralização, fruto das concepções advindas dos métodos ginásticos europeus, estes por sua vez, ancorados nos preceitos e contextos de seus países de origem. 
No contexto do projeto higienista e de eugenização da população brasileira, a Ginástica constituiu-se como elemento de extrema importância, na perspectiva de adestrar e alterar os corpos produzidos por quase três séculos de colonização, conforme Oliveira (1994).

No que diz respeito à esportivização da Ginástica, tal processo tem sua gênese na Inglaterra. Segundo Soares (1994), diferente dos outros países da Europa, nos quais desenvolveram-se as principais escolas de ginástica - França, Alemanha e Suécia, a Inglaterra deu ênfase ao desenvolvimento do desporto. Para Rouyer (1977), isto foi devido ao grande desenvolvimento das forças produtivas neste país que conduziu mais depressa à transformação das relações sociais. Neste sentido, a riqueza e a liberdade das classes dirigentes permitia-lhes o ócio marcado pela lei do dinheiro, em que apostava-se em cavalos, depois em corredores a pé e mais tarde em semiprofissionais. O desporto constituiu-se então como atividade de ócio da aristocracia e da alta burguesia, além de meio de educação social de seus filhos, ao mesmo tempo em que se tornava o trabalho de numerosos profissionais. Assim, a Inglaterra burguesa deu ao mundo o desporto moderno institucionalizado e com regras precisas.

Desta forma, aliada à racionalização científica e às regras do esporte moderno, a Ginástica se transforma em um esporte de rendimento à qual poucos têm acesso. Ou seja, as expressões gímnicas esportivizamse e a sociedade contemporânea herda a ginástica como prática elitizada, o que contribui paulatinamente para sua exclusão da escola.

\section{GINÁSTICA GERAL E EDUCAÇÃO FÍSICA ESCOLAR: POSSIBILIDADES DE ENCONTRO}

Compreendemos a GG como uma esfera da vida social, que, como todas as outras, influencia e é influenciada pela sociedade. Sendo assim, não podemos falar sobre a GG isolada das outras atividades da vida humana, pois desta forma corremos o risco de formar conceitos parciais e simplistas.

A Europa atualmente é o principal centro de desenvolvimento e prática da GG. Segundo Souza (1997), este fato se confirma ao observarmos o grande número de clubes e praticantes. A crescente popularidade desta modalidade pelo mundo pode ser averiguada pelos festivais que são promovidos nos mais diversos países. Em alguns países 
é denominada apenas de Ginástica sem o complemento Geral, a exemplo da Dinamarca que tem no DGI (Associação Dinamarquesa de Ginástica e Esporte) sua maior expressão nesta modalidade, em que cerca de $30 \%$ da população é associada.

É importante salientar que as outras modalidades de Ginástica são consideradas de competição, como a ginástica artística, a ginástica rítmica, dentre outras. Já a GG está orientada para as questões educacionais e do lazer, para a prática sem fins competitivos, privilegiando a demonstração.

Conforme Souza (1997), os princípios que norteiam a GG privilegiam o estímulo à criatividade, ao bem-estar, à união entre as pessoas e o prazer pela sua prática. Sua riqueza está exatamente no princípio de privilegiar todas as formas de trabalho, estilos, tendências, influenciados por uma variedade de tradições, simbolismos e valores que cada cultura agrega. Por este motivo, ao apresentarmos uma possível conceituação, não o fazemos no sentido de cristalizá-lo ou reduzir o fenômeno, pois assim não compreenderíamos sua imensa possibilidade de representação.

A GG, de acordo com o General Gymnastics Manual (FIG, 1993) compreende as seguintes atividades:

- Ginástica e Dança: Dança teatro, Dança Moderna, Dança Aeróbica; Ballet, Folclore, Ginástica Jazz, Ginástica rítmica, Ginástica de Solo, Ginástica Aeróbica, Rock'n Roll, Condicionamento Físico;

- Exercício com aparelhos: Ginástica com aparelhos de grande porte (cavalo, paralelas, etc.), Ginástica com aparelhos manuais (bolas, fitas, arcos, etc.), Ginástica com aparelhos não convencionais (caixas, galões de água, bambus, dentre outros), Tumbling, Trampolim, Rodas, Acrobacias;

- Jogos: Pequenos Jogos, Jogos de Condicionamento Físico, Jogos Sociais, Jogos Esportivos, Jogos de Reação.

Ayoub (2003) projeta algumas imagens da GG, no intuito de visualizar os pilares fundamentais que a sustentam, os quais estão ligados à concepção de GG da Federação Internacional de Ginástica (FIG), que segundo esta autora vem influenciando as ações na área em diversos países, inclusive no Brasil:

- Não possui finalidade competitiva e está situada num plano diferente das modalidades gímnicas competitivas, num plano básico, com a abertura para o divertimento, o prazer, o simples, o diferente, para a participação de todos. Ou seja, é irrestrita. 
- O principal alvo é a pessoa que pratica, visando promover a integração das pessoas e grupos e o desenvolvimento da ginástica com prazer e criatividade. Portanto, a ludicidade e a expressão criativa são pontos fundamentais.

- Não possui regras rígidas preestabelecidas, pois estimula a amplitude e diversidade, abrindo um leque de possibilidades para a prática da atividade corporal, sem distinção de idade, gênero, número e condição física ou técnica dos praticantes, música ou vestuário, favorecendo ampla participação e criatividade.

- Os festivais se constituem como sua principal manifestação, o que a vincula ao artístico, ao espetáculo.

- Difere-se, portanto, das ginásticas competitivas, cujas principais características são: seletividade, regras rígidas preestabelecidas, caminham no sentido da especialização, comparação formal, classificatória e por pontos, visando, sobretudo, o vencer.

Ayoub (2003) aponta ainda que as diferenças entre a GG e as ginásticas competitivas não podem ser vistas de forma rígida e estanque, pois estas convivem interligadas na sociedade e exercem influências recíprocas.

No Brasil, existem vários grupos de Ginástica Geral, apesar de sua prática ser pouco difundida. Dentre eles, se destaca o Grupo Ginástico Unicamp, que tem como proposta não só a prática da Ginástica Geral, mas também a pesquisa do tema na Educação Física Escolar, além da sua abordagem como atividade comunitária.

A proposta do Grupo Ginástico Unicamp - GGU (Grupo de Pesquisa em Ginástica Geral da Faculdade de Educação Física da Unicamp), tem seu enfoque nas relações pedagógicas que foram desenvolvidas em diversas experiências no decorrer de 15 anos, dando uma nova perspectiva de atuação ou instrumentalização para os profissionais de Educação Física. O GGU coloca-se como um "Banco de idéias" para os professores utilizarem-se do universo da Ginástica Geral em suas aulas como metodologia da Educação Física Escolar e Comunitária.

Para o GGU, a Ginástica Geral é entendida como uma manifestação da Cultura Corporal que, reunindo as diferentes interpretações da Ginástica (Natural, Construída, Artística, Rítmica Desportiva, Aeróbica, entre outras), busca integrá-las com outras formas de expressão corporal (Dança, Folclore, Jogos, Teatro, Mímica...) de forma livre e criativa, de acordo com as características do grupo social, visando a contribuir para 
o aumento da interação social entre os participantes (PÉREZ GALLARDO; SOUZA,1997).

Devido às características regionais brasileiras, encontram-se focos de conservações culturais que revelam formas muito peculiares de exploração e adaptação ao meio ambiente, tais manifestações culminam em diferenças culturais "contadas" no folclore, "jogadas", "dançadas", etc., contendo uma riqueza plástica e artística expressa através do movimento. A interação da GG com estas linguagens pode incentivar os praticantes a explorarem as diversas linguagens culturais, ampliando suas experiências e conhecimentos acerca da diversidade cultural brasileira, por exemplo. Outras tematizações, porém, podem e devem ser trabalhadas, permitindo a criação e a ampliação do conhecimento relativo à ginástica associada às questões sociais.

Segundo Ayoub,

Aprender ginástica geral na escola significa, portanto, estudar, vivenciar, conhecer, compreender, perceber, confrontar, interpretar, problematizar, compartilhar, apreender as inúmeras interpretações da ginástica para, com base nesse aprendizado, buscar novos significados e criar novas possibilidades de expressão gímnica.

Sob essa ótica, podemos considerar que a ginástica geral, como conhecimento a ser estudado na educação física escolar, representa a Ginástica. Considerando ainda, as características fundamentais da GG, podemos afirmar que a ginástica traz consigo a possibilidade de realizarmos uma reconstrução da ginástica na educação física escolar numa perspectiva de "confronto" e síntese e, também, numa perspectiva lúdica, criativa e participativa (2003, p. 87).

O princípio norteador desta proposta, ao nosso ver, deve privilegiar a formação humana em sua totalidade. Desse prisma, a proposta de trabalho em Ginástica Geral propõe a educação a serviço de novos valores, manifestados e gerados na sociedade e na vivência do lúdico na cultura, sendo os participantes agentes da história, em busca da transformação social. 
General gymnastics at school: A methodological propositon

\begin{abstract}
This study aims at discussing gym classes as a part of school physical education, using General Gymnastics as a methodological approach. Such an approach has the perspective of integrating the several gymnastic manifestations to the other components of body culture, with the lack of competition as its main feature.

KEY WORDS: gym - general gymnastics - physical education in schools.
\end{abstract}

Gimnasia general en la escuela: Una propuesta metodológica

\title{
RESUMEN
}

Este trabajo tiene por objetivo discutir la Gimnasia como contenido de la Educación Física escolar, por medio de la Gimnasia general como propuesta metodológica. Tal propuesta tiene como perspectiva la integración de diversas manifestaciones gímnicas y los otros componentes de la cultura corporal, siendo su principal característica la ausencia de la competencia.

PALABRAS-CLAVE: gimnasia - gimnasia general - educación física escolar.

\section{REFERÊNCIAS}

AYOUB, Eliana. Ginástica geral e educação física escolar. Campinas, SP: Unicamp, 2003.

COLETIVO DE AUTORES. Metodologia do ensino de educação física. São Paulo: Cortez, 1992.

FÉDÉRATION INTERNATIONALE DE GYMNASTIQUE (FIG). General gymnastics manual. Moutier: 1993.

OLIVEIRA, V. M. de. Consenso e conflito da educação física brasileira. Campinas: Papirus, 1994.

PÉREZ GALLARDO, J. S., SOUZA, E. P. M. A proposta de ginástica geral do Grupo Ginástico Unicamp. In: AYOUB, E., SOUZA, E. P. M., PÉREZ GALLARDO, J. S. (Orgs.). Coletânea de textos e sínteses do I e II Encontro de Ginástica Geral. Campinas: Gráfica Central da Unicamp, 1997. p.25-32.

ROUYER, J. Pesquisas sobre o significado humano do desporto e dos tempos livres e problemas da história da educação física. In: ROUYER, 
J. Desporto e desenvolvimento humano. Lisboa, Portugal: Seara Nova, 1977. p.159-195.

SOARES, C. Educação física: raízes européias e Brasil. Campinas: Papirus, 1994.

Imagens da educação no corpo: estudo a partir da ginástica francesa no século XIX. Campinas: Papirus, 1998.

Corpo, conhecimento e educação: notas esparsas. In: SOARES, C. (Org.). Corpo e história. Campinas: Autores Associados, 2001. p.109-129.

SOUZA, E. P. M. Ginástica geral: uma área do conhecimento da educação física. Tese de doutorado, Faculdade de Educação Física, Universidade Estadual de Campinas. Campinas, SP: 1997.

Recebido: 30 de abril de 2004

Aprovado: junho de 2004

Endereço para correspondência Rua Pantojo, 1353 - Vila Regente Feijó Apto. $25 \mathrm{~K}$ - São Paulo - SP

CEP 03343-000

E-mail: narinharejane@aol.com.br 